\title{
PENCAPAIAN PERANAN BKK DALAM PENYALURAN LULUSAN TEKNIK PENGELASAN DI SMK DIY
}

\author{
Darunnajah $^{1}$, Putut Hargiyarto ${ }^{2}$ \\ 1,2Pendidikan Teknik Mesin Fakultas Teknik Universitas Negeri Yogyakarta \\ E-mail: darunnajah210ft@student.uny.ac.id
}

\begin{abstract}
This research aims to study the achievement of Special Labor Market's roles in the distribution of the welding study program graduates through the management process (planning, organizing, actuating, and controlling), and the obstacles that occurred. This research also study students' perception of the Special Labor Market (BKK) work program. The methods of this research is descriptive research. The instruments for data collection are questionnaire, interviews, and documentation. Data were analyzed using descriptive qualitative analysis. The research samples are the 5 leaders of BKK and 117 class XII students of welding study program. Result of the research indicate the following scores of the management process aspects: planning 85,6\%, organizing 78,3\%, actuating 80,3\%, and controlling 93,1\%. The distribution that have been carried out still puts the workforce out of their field of expertise. The obstacles that occurred during the distribution are: graduates are not ready to work out of their hometown or the parents did not give permission for them to work outside their hometown. The overall graduates' perception towards the implementation of labor market work program related to graduates is in the category of 'good' with a score of $66,5 \%$.
\end{abstract}

Keywords: specific labor market, management process, welding

\begin{abstract}
ABSTRAK
Penelitian ini bertujuan untuk mengetahui: 1) capaian peranan BKK dalam penyaluran lulusan teknik pengelasan melalui proses manajemen dan 2) persepsi siswa terhadap program kerja BKK yang berhubungan langsung dengan siswa dan alumni. Penelitian ini menggunakan metode penelitian deskriptif. Teknik pengumpulan data menggunakan instrumen angket, wawancara, dan dokumentasi. Analisis data menggunakan teknik analisis deskriptif kuantitatif. Sampel penelitian adalah 5 Ketua BKK dan 117 Siswa Kelas XII Teknik Pengelasan di wilayah Yogyakarta. Hasil penelitian menunjukan bahwa skor proses manajemen BKK pada aspek perencanaan $85,6 \%$, aspek pengorganisasian $78,3 \%$, aspek pelaksanaan $80,3 \%$, dan aspek pengendalian $93,1 \%$. Penyaluran yang dilaksanakan masih menempatkan lulusan bekerja di luar bidang keahliannya. Hambatan yang dihadapi adalah terdapat lulusan yang belum siap untuk bekerja di industri luar kota dan orang tua lulusan yang belum memberi ijin lulusan untuk bekerja di industri luar kota. Persepsi siswa secara keseluruhan terhadap pelaksanaan program BKK yang berkaitan dengan siswa dan alumni termasuk dalam kategori baik dengan persentase sebesar $66,5 \%$.
\end{abstract}

Kata kunci: bursa kerja khusus, proses manajemen, teknik pengelasan

\section{PENDAHULUAN}

Industri manufaktur sedang mengalami perkembangan di Indonesia. United Nations Statistics Division mencatat pada tahun 2016 Indonesia menempati peringkat keempat dunia yang industri manufakturnya dapat memberikan kontribusi terhadap Produk Domestik Bruto (PDB) dengan persentase sebesar 22\%, Korea Selatan 29\%, Tiongkok 27\%, dan Jerman 23\%.
(Kemenperin. 2018). Industri manufaktur membutuhkan tenaga kerja pengelasan dalam kegiatannya. Tenaga kerja pengelasan bertugas menyambung benda yang terbuat dari logam. Seorang tenaga kerja pengelasan harus mengetahui kondisi pasar kerja pengelasan agar dapat memperoleh pekerjaan.

Pasar kerja pengelasan merupakan kegiatan transaksi produktif antara tenaga 
pengelasan dengan pihak industri. Asosiasi Pengelasan Indonesia (API) mencatat industri manufaktur nasional memerlukan 5.000 tenaga pengelasan pertahun. Balai Besar Bahan dan Barang Teknik (B4T) Bandung mengatakan bahwa tingkat kualifikasi tenaga kerja pengelasan yang dibutuhkan dalam industri manufaktur antara lain welding coordiantor, welder, welding inspector, dan nondestructive testing personnel. (Annisa, 2017). Perkembangan Industri manufaktur menjadi tantangan bagi masyarakat yang berminat di bidang pengelasan. Masyarakat perlu dibekali ilmu pengetahuan, kepribadian dan keterampilan pengelasan agar dapat bersaing dalam pasar kerja. Sarana yang dapat membantu masyarakat adalah Sekolah Menegah Kejuruan.

Nirmala dan Wagiran menjelaskan bahwa Sekolah Menegah Kejuruan (SMK) adalah pendidikan formal yang diharapkan mampu mempersiapkan sumberdaya manusia sebagai calon tenaga kerja tingkat menegah berkualitas. Keberadaan SMK menjadi harapan bagi masyarakat yang ingin memperoleh pekerjaan setelah lulus. Lulusan SMK di Indonesia masih banyak yang kesulitan dalam mendapatkan pekerjaan. Badan Pusat Statistik (BPS) tahun 2017 mencatat angka pengangguran di Indonesia meningkat dari 7,03 juta orang menjadi 7,04 juta orang. Jumlah pengangguran tertinggi terdapat pada lulusan SMK dengan persentase sebesar 11,41\%. (Pramdia, 2017). SMK membutuhkan lembaga yang dapat menjadi jembatan kerjasama antara sekolah dengan industri. Lembaga tersebut adalah Bursa Kerja Khusus.

Hermansyah (2010:11) menyatakan bahwa Bursa Kerja Khusus (BKK) adalah lembaga yang berfungsi mempertemukan pencari kerja dan pengguna tenaga kerja untuk penempatan tenaga kerja. BKK membutuhkan proses manajemen yang baik agar kegiatannya dapat berjalan lancar. Menurut Hani (2017:8) proses manajemen meliputi perencanaan (planning), pengorganisasian (organizing), pelaksanaan (actuating), dan pengendalian (controlling).
BKK dapat melaksanakan program kerja yang sesuai dengan fungsinya. Direktorat PSMK (2017) menyatakan bahwa program kerja BKK meliputi penyusunan database, penjaringan lowongan kerja, pemasaran lulusan, penyaluran lulusan, penjajakan dan verifikasi, pelatihan tambahan, bimbingan karir, dan penyampaian info lowongan kerja. Menurut Thomas Sukardi dan Putut Hargiyarto (2007:150) pengurus BKK dapat menggunakan strategi khusus dalam programnya seperti pemberian informasi lowongan kerja, pendataan pencari kerja, bimbingan karir, penyaluran dan penempatan tenaga kerja.

Strategi yang dapat digunakan oleh BKK salah satunya adalah pelaksanaan bimbingan karir terhadap siswa. Bimbingan karir dapat memberikan kesiapan siswa untuk memasuki dunia kerja. Hal ini sejalan dengan penelitian Simholis Dwi (2014). Hasil penelitian menunjukkan bahwa pelaksanaan bimbingan karir dapat memberikan kontribusi positif dan signifikan terhadap kesiapan lulusan untuk memasuki dunia kerja.

Penelitian ini dilakukan di SMK Negeri 1 Pundong, SMK Negeri 1 Sedayu, SMK Negeri 2 Pengasih, SMK Negeri 2 Wonosari, dan SMK Muhammadiyah 2 Wates. Kelima SMK tesebut merupakan SMK yang memiliki paket keahlian teknik pengelasan. Hasil penelusuran Lulusan Teknik Pengelasan selama 3 tahun terakhir memperlihatkan bahwa masih terdapat lulusan yang belum mendapatkan pekerjaan. SMK Negeri 1 Pundong berhasil meluluskan 172 siswa teknik pengelasan dengan jumlah persentase alumni yang bekerja $81.4 \%$, melanjutkan studi $5.2 \%$, belum bekerja $2.3 \%$, dan sisanya belum terlacak. SMK Negeri 1 Sedayu pada tahun 2015 dan 2016 berhasil meluluskan 176 siswa teknik pengelasan dengan jumlah persentase alumni yang bekerja 69.9\%, melanjutkan studi $15.9 \%$, mengganggur $0 \%$ dan sisanya belum terlacak. SMK Negeri 2 Pengasih meluluskan sebanyak 95 siswa keahlian teknik pengelasan dengan persentase alumni yang telah bekerja sebanyak 56,8\%, melanjutkan studi $10,5 \%$, belum bekerja $10,5 \%$, dan sisanya belum 
terlacak. SMK Negeri 2 Wonosari meluluskan 94 siswa teknik pengelasan dengan jumlah persentase alumni yang bekerja 62,8\%, melanjutkan studi $15,9 \%$, belum bekerja 7,5 dan sisanya belum terlacak. SMK Muhammadiyah 2 Wates meluluskan 92 siswa teknik pengelasan dengan jumlah persentase alumni yang telah bekerja $80,4 \%$, melanjutkan studi $2,2 \%$, belum bekerja 10,9\%, dan sisanya belum terlacak.

BKK dikatakan berhasil apabila dapat menyalurkan seluruh lulusannya menuju ke dunia usaha/dunia industri (DU/DI) sesuai dengan bidang keahliannya. Berdasarkan hal itu, maka perlu dilakukan penelitian untuk mengetahui peranan BKK dalam penyaluran lulusan teknik pengelasan dan faktor yang dapat menghambat pelaksanaan penyaluran lulusan di SMK Teknik Pengelasan DIY.

\section{METODE}

Penelitian ini menggunakan jenis penelitian deskriptif. Menurut Misbahuddin \& Iqbal (2014:9) penelitian deskriptif adalah penelitian yang dilakukan untuk mempelajari masalah dalam masyarakat, tata cara yang berlaku, situasi tentang hubungan, kegiatan, sikap, pandangan, serta proses yang berlangsung dan berpengaruh dari suatu fenomena. Penelitian ini akan menggambarkan fenomena tentang peranan BKK di SMK Pengelasan DIY.

Penelitian dilaksanakan pada bulan Maret-Mei 2018. Subjek penelitian ini adalah 5 ketua BKK dan 117 Siswa Kelas XII Teknik Pengelasan. Teknik pengambilan sampel penelitian ini menggunakan teknik cluster sampling.

Prosedur penelitian ini meliputi perencanaan penelitian (observasi, wawancara, pembuatan instrumen penelitian, dan validasi instrumen), pelaksanaan penelitian (angket, wawancara, dan dokumentasi), dan analisi data. Data angket penelitian diolah ke dalam bentuk persentase dengan menggunakan bantuan software microsoft excel 2010. Data wawancara dan dokumentasi direduksi untuk menentukan data yang sesuai dengan tema penelitian.

Metode pengumpulan data penelitian ini menggunakan instrumen angket, wawancara, dan dokumentasi. Data ketua BKK diperoleh melalui instrumen angket, wawancara, dan dokumentasi. Data persepsi Siswa Kelas XII Teknik Pengelasan diperoleh melalui angket. Teknik analisis data pada penelitian menggunakan analisis deskriptif kuantitatif. Hasil perolehan angket penelitian akan diolah ke bentuk persentase menggunakan software microsoft excel 2010. Data angket penelitian dapat dianalisis menggunakan Persamaan (1).

Persentase $=\frac{\text { total perolehan skor }}{\text { skor maksimun }} \times 100 \%$.... (1)

Data yang telah diolah dalam bentuk persentase akan diubah menjadi data kualitatif dengan menggunakan kriteria ketercapaian menurut Riduwan (2007: 12) pada Tabel 1.

Tabel 1. Persentase dan Kategori Ketercapaian

\begin{tabular}{cc}
\hline Presentase & Kategori \\
\hline $80 \leq \mathrm{x} \leq 100$ & Sangat baik \\
$60 \leq \mathrm{x} \leq 80$ & Baik \\
$40 \leq \mathrm{x} \leq 60$ & Cukup \\
$20 \leq \mathrm{x} \leq 40$ & Kurang \\
$0 \leq \mathrm{x} \leq 20$ & Sangat kurang \\
\hline
\end{tabular}

Data kualitatif wawancara dan dokumentasi dirangkum dan dipilih sesuai dengan tema dan pola penelitian. Data penelitian direduksi untuk memberikan dapat memberikan gambaran yang lebih jelas dari hasil penelitian.

\section{HASIL DAN PEMBAHASAN}

Data hasil penelitian manajemen BKK pada aspek perencanaan secara keseluruhan dapat dilihat pada Gambar 1. 


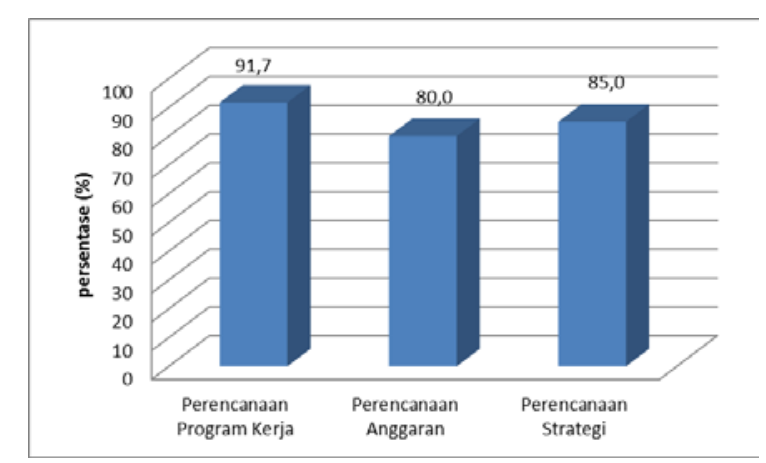

Gambar 1. Diagram Aspek Perencanaan BKK

Perencanaan program kerja secara keseluruhan termasuk dalam kategori baik sekali. Pengurus BKK membuat perencanaan program kerja menggunakan pedoman yang diberikan oleh Disnakertrans dan Depnaker. Perencanaan anggaran secara keseluruhan dalam kategori baik sekali. Perencanaan anggaran disesuaikan dengan kebutuhan program kerja. Biaya anggaran yang digunakan berasal dari kas BKK. Perencanaan strategi secara keseluruhan termasuk dalam kategori sangat baik. Pengurus BKK menggunakan strategi pendekatan dan kerjasama yang baik dengan pihak industri yang memiliki profil sesuai standar Disnakertrans, Depnaker, dan sekolah sehingga dapat memperbesar peluang keberhasilan program penyaluran tamatan/tenaga kerja.

Data hasil penelitian pada aspek pengorganisasian BKK dapat dilihat pada Gambar 2.

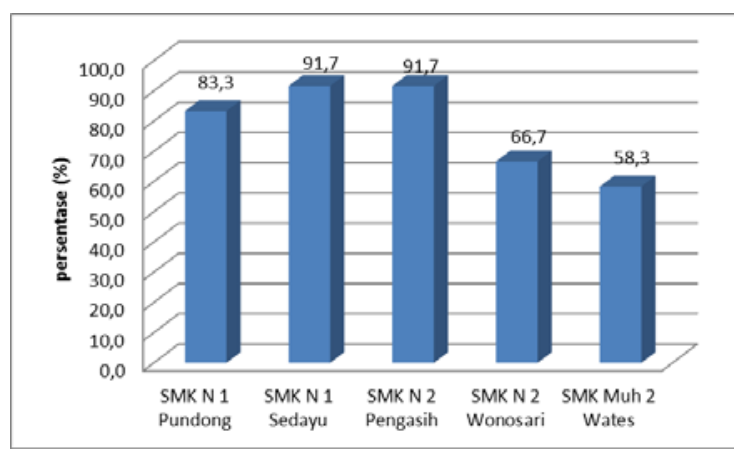

Gambar 2. Diagram Aspek Pengorganisasian BKK

Pembentukan struktur organisasi BKK secara keseluruhan termasuk dalam kategori baik. organisasi BKK sudah memiliki struktur yang jelas tetapi dalam kegiatannya beberapa pengurus masih belum melaksanakan tugasnya. Hal ini dikarenakan pengurus BKK juga merupakan guru mengajar sehingga sedik kesulitan untuk membagi waktu mengajar dan mengurus BKK.

Data hasil penelitian manajemen BKK pada aspek pelaksanaan program kerja BKK dapat dilihat pada Gambar 3.

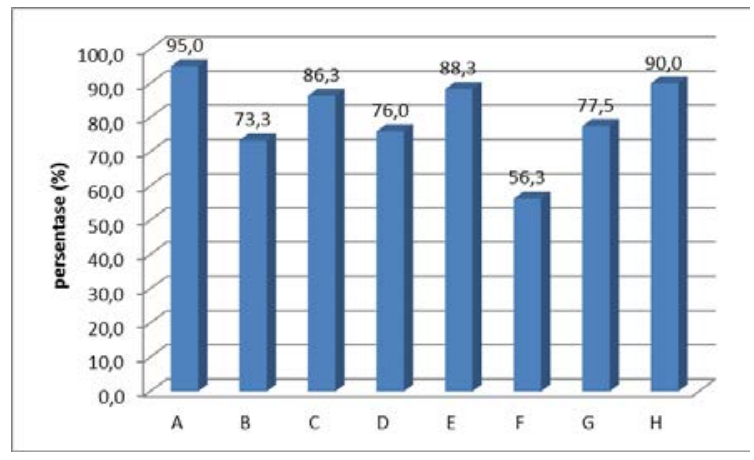

Gambar 3. Diagram Aspek Pelaksanaan Program Kerja BKK
Keterangan:
$\mathrm{A}=$ Penyusunan data base
$\mathrm{B}=$ Penjaringan lowongan kerja
$\mathrm{C}=$ Pemasaran calon tenaga kerja
$\mathrm{D}=$ Penyaluran tenaga kerja
$\mathrm{E}=$ Penjajakan dan verifikasi
$\mathrm{F}=$ Pelatihan tambahan
$\mathrm{G}=$ Bimbingan jabatan/karir
$\mathrm{H}=$ Penyampaian info lowongan kerja

Penyusunan data base secara kesuluruhan termasuk dalam kategori sangat baik. Pengurus BKK masing-masing sekolah melakukan pendataan calon tenaga kerja teknik pengelasan, industri pengelasan, dan penelusuran tamatan. Pendataan yang dilakukan masih bersifat umum sehingga belum dipisah antara paket keahlian teknik pengelasan dan paket keahlian lain.

Penjaringan lowongan pekerjaan secara keseluruhan termasuk dalam kategori baik. Pengurus BKK menjaring lowongan kerja dari kerjasama dengan pihak industri, BKK SMK lain, Disnakertrans, dan Depnaker. Pengurus BKK lebih dahulu memeriksa latar belakang industri yang menawarkan lowongan pekerjaan untuk memastikan industri tersebut telah sesuai 
standar dari Disnakertrans, Depnaker, dan sekolah.

Pemasaran calon tenaga kerja secara keseluruhan termasuk dalam kategori sangat baik. Pemasaran calon tenaga kerja dilakukan minimal setahun sekali dengan memberikan informasi tantang potensi lulusan. Pelaksanaan penawaran calon tenaga kerja dilaksanakan saat siswa melakukan kunjungan industri dan saat siswa telah melaksanakan ujian nasional. Penyaluran tenaga kerja secara keseluruhan termasuk dalam kategori baik. Penyaluran tenaga kerja masih menempatkan tenaga kerja bekerja di luar bidang keahliannya. Faktor utamanya adalah terdapat lulusan yang belum siap bekerja di luar kota dan orang tua yang belum memberikan izin lulusan untuk bekerja di luar kota.

Penjajakan dan verifikasi secara keseluruhan termasuk dalam kategori baik sekali. Penjajakan dan verifikasi meliputi pendataan tenaga kerja dan monitoring tenaga kerja tersalurkan. Monitoring dilaksanakan lewat kunjungan industri dan komunikasi lewat telepon dengan tenaga kerja dan pihak industri.

Pelatihan tambahan secara keseluruhan termasuk dalam kategori sedang. Pelatihan tambahan diberikan oleh balai latihan kerja (BLK) kabupaten/kota, industri, dan Disnakertrans. Pihak tersebut dirasa lebih berkompeten dalam memberikan pelatihan tambahan. Pelatihan tambahan diberikan setelah siswa melaksanakan ujian nasional. Bimbingan jabatan/karir secara keseluruhan termasuk dalam kategori baik. Pengurus BKK memberikan materi bimbingan jabatan/karir kesiapan masuk dunia industri dan langkah agar dapat lolos seleksi masuk kerja. Siswa juga diajarkan cara bersikap yang baik di dunia industri.

Penyampaian info lowongan kerja secara keseluruhan dalam kategori baik sekali. Pengurus BKK menyampaikan informasi lewat media sosial whatsapp. Media tersebut dirasa lebih efektif dan cepat untuk menyampaikan informasi lowongan kerja.
Data hasil penelitian manajemen BKK secara keseluruhan pada aspek pengendalian BKK dapat dilihat pada Gambar 4.

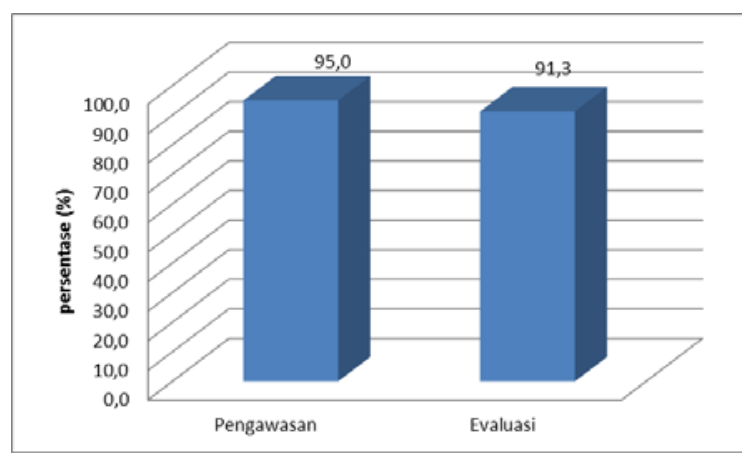

Gambar 4. Diagram Aspek Pengendalian BKK

Pengawasan BKK secara keseluruhan termasuk kategori baik sekali. Pihak internal yang mengawasi kegiatan BKK adalah kepala sekolah dan waka humas BKK, sedangkan pihak luar adalah Dinakertrans, Depnaker dan polisi.

Evaluasi program kerja secara keseluruhan termasuk dalam kategori baik sekali. Pengurus BKK melaporkan hasil pelaksanaan program kerja dan biaya yang digunakan kepada kepala sekolah. Hasil evaluasi program kerja digunakan untuk menentukan perencanaan masa depan BKK. Pengurus BKK berencana memperluas kerjasama dengan industri yang memiliki profil yang sesuai dengan standar yang ditentukan sehingga dapat memperbesar persentase penyaluran lulusan/tenaga kerja.

Pelaksanaan kegiatan BKK tidak bisa terhindar dari hambatan yang terjadi. Hambatan utama yang muncul adalah lulusan belum siap bekerja di luar kota dan orang tua belum memberikan ijin untuk bekerja di luar kota. Hambatan lain adalah lulusan mengganti nomer telepon tanpa memberitahu BKK, kurangnya personil dalam organisasi, kurangnya dukungan dana dari pihak sekolah.

Data hasil penelitian tentang persepsi siswa terhadap pelaksanaan program kerja BKK dapat dilihat pada Gambar 5. 


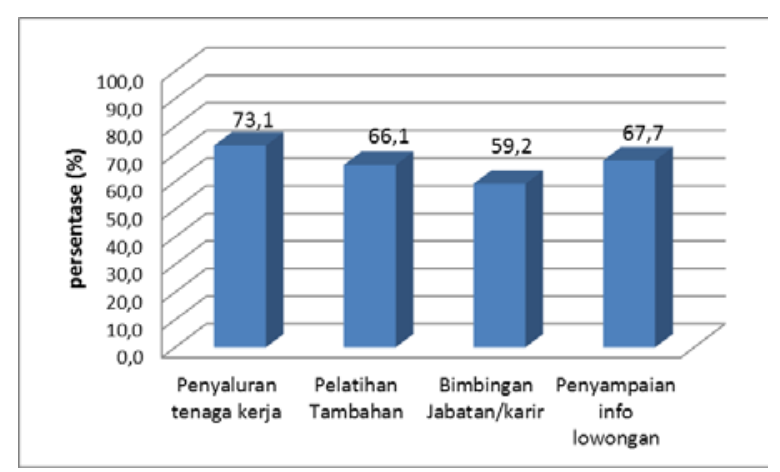

Gambar 5. Diagram Persepsi Siswa terhadap Pelaksanaan Program Kerja BKK

Persepsi siswa secara keseluruhan pada indikator penyaluran tenaga kerja dalam kategori baik dengan persentase $73,1 \%$. Persepsi siswa secara keseluruhan pada indikator pelatihan tambahan dalam kategori baik dengan persentase 59,2\%. Persepsi siswa secara keseluruhan pada indikator bimbingan jabatan dalam kategori sedang dengan persentase 59,2\%. Persepsi siswa secara kesuluruhan pada indikator penyampaian informasi lowongan pekerjaan dalam kategori baik dengan persentase $66,7 \%$.

Hasil persepsi siswa yang diperoleh menurut peneliti kurang sesuai kenyataan. Hal ini dikarenakan siswa terlihat kurang serius dalam mengisi angket penelitian.

\section{SIMPULAN}

Aspek perencanaan BKK secara keseluruhan termasuk dalam kategori baik sekali dengan persentase 85,6\%. Perencanaan BKK meliputi perencanaan program kerja, perencanaan anggaran, dan perencanaan strategi. Aspek pengorganisasian BKK termasuk dalam kategori baik dengan persentase 78,3\%. Pengurus BKK sudah memiliki struktur organisasi tetapi beberapa pengurus masih belum melaksanakan tugasnya. Aspek pelaksanaan program kerja termasuk dalam kategori baik sekali dengan persentase $80,3 \%$. BKK telah melaksanakan program kerja sesuai dengan pedoman dari Direktorat PSMK. Aspek pengendalian BKK termasuk dalam kategori baik sekali dengan persentase 93,1\%. Kegiatan BKK diawasi dan dikendalikan oleh kepala sekolah, Disnakertrans, dan kepolisian setempat. Hambatan utama dalam penyaluran lulusan adalah terdapat lulusan yang belum siap bekerja di industri luar kota dan orang tua yang belum memberikan ijin. Hal ini menyebabkan lulusan kesulitan dalam memperoleh pekerjaan yang sesuai dengan keahliannya. Persepsi siswa terhadap pelaksanaan program kerja secara keseluruhan termasuk dalam kategori baik dengan persentase $66.5 \%$. Siswa menilai BKK telah memberikan pelayanan kepada siswa maupun alumni teknik pengelasan.

\section{DAFTAR RUJUKAN}

Annisa Sulistyo Rini. (2017). Industri Manufaktur Butuh 5.000 Tenaga Las Per Tahun, Ini Kualifikasinya. Diakses pada tanggal 19 Januari 2018 dari situs http://industri.bisnis.com/read/20171112/ 257/708276/industri-manufaktur-butuh5.000-tenaga-las-per-tahun-ini-kualifikas inya

Direktorat PSMK-Subdit LASJURIN. (2017). Bursa Kerja Khusus. Diakses pada tanggal 16 Februari 2018 dari situs http://bkk.ditpsmk.net/about

T. Hani Handoko (2017). Manajemen. Yogyakarta: BPFE-Yogyakarta.

Hermansyah, Marsudi, Hani Rochmanudi. (2010). Manajemen Bursa Kerja Khusus untuk SMK. Yogyakarta: Paramita Publishing.

Kemenperin. (2018). Kontribusi Manufaktur RI Tertinggi di ASEAN. Diakses pada tanggal 19 Januari 2018 dari http://www.kemenperin.go.id/artikel/186 11/Kontribusi-Manufaktur-RI-Tertinggidi-ASEAN

Misbahuddin \& Iqbal Hasan. (2014). Analisis Data Penelitian dengan Statistik. Jakarta: PT Bumi Aksara.

Nirmala Adhi Yoga P. \& Wagiran. (2014). Kinerja Bursa Kerja Khusus (BKK) SMK Negeri Bidang Keahlian Teknologi dan Rekayasa di Kabupaten Sleman. Jurnal Pendidikan Vokasi, 4 (2), 246-261. 
Pramdia Arhando Julianto. (2017). Agustus 2017, Jumlah Pengangguran Naik Menjadi 7,04 Juta Orang. Diakses pada tanggal 19 Januari 2018 dari situs https://ekonomi.kompas.com/read/2017/1 1/06/153940126/agustu-2017-jumzlahpengangguran-naik-menjadi-704-jutaorang.

Putut Hargiyarto \& Thomas Sukardi. (2007). Peran Bursa Kerja Khusus Sebagai Upaya Penempatan Lulusan SMK dalam Rangka Terwujudnya Link And Match Antara Sekolah dengan Dunia Industri. Jurnal Pendidikan Teknologi dan Vokasi, 16 (2), 142-163.
Riduwan. (2007). Skala Pengukuran Variabelvariabel Penelitian. Bandung: Alfabeta.

Simholis Dwi. (2014). Kontribusi Minat Kerja dan Bimbingan Karir terhadap Kesiapan Memasuki Dunia kerja. Jurnal Pendidikan Teknik Mesin, 3 (2), 193-200. 